\title{
PRODUÇÃO ANIMAL
}

\section{CARACTERÍSTICAS FERMENTATIVAS DA SILAGEM DE HÍBRIDOS DE SORGO SOB DOSES DE NITROGÊNIO}

\author{
Aldi Fernandes de Souza França ${ }^{1}$, Régis de Paula Oliveira², José Avelino Santos

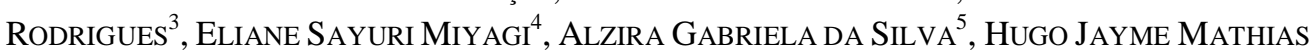 \\ COElHo PERON ${ }^{6}$, João Batista Rodrigues de Abreu $^{7}$, Débora de CARVAlHo Bastos ${ }^{2}$
${ }^{1}$ Professor Titular, Doutor, Departamento de Produção Animal EV/UFG, Goiânia, GO. Campus II. CEP 74.001-970e-mail: aldi@vet.ufg.br.
${ }^{2}$ Zootecnista, Mestre em Produção Animal
${ }^{3}$ Pesquisador Embrapa Milho e Sorgo - Sete Lagoas, MG
${ }^{4}$ Zootecnista, D.Sc. Bolsista PRODOC/CAPES - EV /UFG, Goiânia-GO
${ }^{5}$ Doutoranda do Programa de Pós-graduação em Ciência Animal - EV/UFG, Goiânia, GO.
${ }^{6}$ Graduando do curso de Medicina Veterinária - EV/UFG, Goiânia, GO.
${ }^{7}$ Professor Associado, doutor, Instituto de Zootecnia, UFRRJ, Seropédica, RJ.

\begin{abstract}
RESUMO
Foram avaliadas as características fermentativas das silagens de quatro híbridos de sorgo forrageiro sob doses de nitrogênio, em função dos teores de matéria seca da matéria original (MSmo) e da silagem (MSs), proteína bruta da matéria original (PBmo) e da silagem (PBs), $\mathrm{pH}$, ácido lático ( $\mathrm{AL}$ ), ácido acético (AC), ácido bútirico (AB), ácido propiônico (AP), densidades da silagem no momento de enchimento (Den) e na abertura dos silos (Dab), produção de gás (Gás) e efluentes (Efl). Utilizouse o delineamento de blocos casualizados em esquema fatorial $4 \times 3$, com quatro repetições. Os cultivares foram 1F 305, 0369 267, 0369255 e BR 700, sob três doses de $\mathrm{N}$ (0; 60 e $120 \mathrm{~kg} \mathrm{ha}^{-1}$ ). Foram observadas interações entre as doses de $\mathrm{N}$ e os híbridos avaliados em relação aos teores de MSmo, com variação de 21,82 a $28,17 \%$. Os valores de MSs diferiram $(\mathrm{P}<0,05)$ apenas entre os

híbridos 1F305 e 0369 267, com médias de 27,6 e 27,8\%, respectivamente. A concentração de AL diferiu $(\mathrm{P}<0,05)$ entre cultivares e tratamentos com variação de $3,60 \%$ a 4,55\%. Os teores de AC diferiram apenas para o híbrido BR 700 com média de l,4\% e variação de 1,29\% a 1,52\%. $\mathrm{O}$ teor de AP diferiu $(\mathrm{P}<0,05)$ entre os cultivares com variação de $0,17 \%$ a $0,24 \%$. Somente o híbrido 0369255 diferiu $(\mathrm{P}<0,05)$ em relação a Den, com média de 509,9 kg.m ${ }^{-3}$, enquanto em função das doses de $\mathrm{N}$ avaliadas, foram observadas significâncias com as aplicações das doses de 60 e 120 kg.ha $^{-1}$ de $\mathrm{N}$, com médias de 371,2 e $378,3 \mathrm{~kg} . \mathrm{m}^{3}$, para os respectivos tratamentos. Apenas o híbrido 0369255 diferiu $(\mathrm{P}<0,05)$ em relação a Dab, com média de $454,9 \mathrm{~kg} \cdot \mathrm{m}^{-3}$, enquanto a dose equivalente à aplicação de 120 kg.ha $^{-1}$ de $\mathrm{N}$ diferiu $(\mathrm{P}<0,05)$ para todos os genótipos, com média do tratamento de 409,9 kg.m³.
\end{abstract}

PALAVRAS-CHAVE: ácidos graxos voláteis; adubação nitrogenada; padrão de fermentação; pH; Sorghum bicolor

\section{FERMENTATIVE CHARACTERISTICS OF SORGHUM HYBRIDS ENSILAGE UNDER NITROGEN RATES}

The objective of this study was to evaluate four sorghum ensilages under nitrogen rates, regarding the nfermentative characteristics, such as, dry matter content of original matter (DMom) and silage (DMs), crude protein of original matter (CPom) and silage (CPs), $\mathrm{pH}$, tenors of the volatile fatty acids, densities of wadding (Dw) and opening (Do), productions of gas (Gas) and effluent (Efl). The experimental design was in randomized blocks in a $4 \times 3$ factorial arrangement with four replications. The cultivars used in this study were $1 \mathrm{~F}$ 305, 0369 267, 0369 255 and BR 700, and the three rates of nitrogen under ammonium sulphate form were 0; 60 and $120 \mathrm{~kg} \mathrm{N.ha-1}$. 
The tenors of DMmo differed $(\mathrm{P}<0.05)$ among $\mathrm{N}$ rates and the evaluated hybrids, presenting a variation of 21.82 to $28.17 \%$. Values of DMs only differed $(\mathrm{P}<0.05)$ between the hybrids $1 \mathrm{~F} 305$ and 0369 267, with averages of 27.6 and $27.8 \%$, respectively. The concentration of lactic acid differed $(\mathrm{P}<0.05)$ among cultivars and treatments varying from $3.60 \%$ to $4.55 \%$. The tenors of acetic acid differed only for BR 700 , varying from $1.29 \%$ to $1.52 \%$. The tenors of propionic acid differed $(\mathrm{P}<0.05)$ among cultivars, varying from $0.17 \%$ to $0.24 \%$. The densities Dw and Do of the experimental silos did not differ between the hybrids, except the 0369255.

KEYWORDS: fermentative parameters; nitrogen fertilization; $\mathrm{pH}$; Sorghum bicolor; volatile fatty acids

\section{INTRODUÇÃO}

A ensilagem consiste na fermentação anaeróbica de plantas forrageiras e constitui-se numa boa opção de conservação de alimentos volumosos para suplementação no período seco (McDONALD et al., 1991). Seu processo tem sido amplamente estudado com o intuito de suprir as deficiências causadas pelo período, melhorar o valor nutricional da dieta, reduzir os gastos com a utilização de concentrados e otimizar a eficiência produtiva das propriedades.

Diversas gramíneas podem ser utilizadas para produção de silagens. O sorgo (Sorghum bicolor (L.) Moench) é uma planta adaptada ao processo de ensilagem, devido às suas características fenotípicas, tais como facilidade de semeadura, manejo, colheita e armazenamento, aliadas ao alto valor nutritivo, à elevada concentração de carboidratos solúveis, as quais são essenciais para uma adequada fermentação lática, bem como aos altos rendimentos de massa seca por unidade de área (NEUMANN et al., 2002).

O teor de matéria seca (MS) da planta forrageira é um dos fatores determinantes do tipo de fermentação no processo da ensilagem e é variável em função da idade de corte e também da a natureza do colmo da planta (CARVALHO et al., 1992). Segundo McDONALD et al. (1991), os teores de MS acima de $25 \%$, quando associados a um bom nível de carboidratos solúveis, são suficientes para produção de uma silagem de boa qualidade.

As silagens bem preservadas devem apresentar um pH na faixa de 3,7 a 4,2, enquanto que as de baixa qualidade se situam entre 5,0 a 7,0. A boa preservação através da fermentação depende da produção de ácido lático para estabilização do $\mathrm{pH}$ e da adequada quantidade de ácidos orgânicos, o que faz reduzir a capacidade tamponante da forragem (VAN SOEST, 1994). Dentre os principais ácidos orgânicos encontrados na silagem, podem ser citados o lático, acético, butírico, propiônico, valérico e succínico. Entretanto, os três primeiros são os mais determinados, sendo que suas porcentagens e as relações entre ácido lático/acético, dentre outras, são parâmetros de grande validade na avaliação do processo fermentativo das silagens.

Diante dos fatos discorridos acima, objetivou-se avaliar as seguintes características qualitativas das silagens de híbridos de sorgo sob doses de nitrogênio na região de Goiânia-GO: porcentagem de matéria seca, proteína bruta, $\mathrm{pH}$, teores dos ácidos graxos voláteis, densidades de enchimento e abertura, produções de gás e de efluentes

\section{MATERIAL E MÉTODOS}

O experimento foi realizado no município de Goiânia-GO durante o período de 22/11/2003 a 05/06/2004, em área do Departamento de Produção Animal da Escola de Veterinária da Universidade Federal de Goiás, Campus II, localizada na latitude S $16^{\circ} 36^{\prime}$ e longitude $\mathrm{W} 49^{\circ} 16^{\prime}$, com altitude de $727 \mathrm{~m}$. O clima da região, segundo a classificação de Köppen, é do tipo Aw (quente semi-úmido, com estação seca bem definida durante os meses de maio a outubro), com temperatura anual média de $23,20^{\circ} \mathrm{C}$, média mínima de $17,90^{\circ} \mathrm{C}$ e precipitação anual de 1759,90 mm (BRASIL, 1992).

A área experimental foi preparada com uma aração e duas gradagens. Para fins de sua caracterização química, foram coletadas amostras na profundidade de $0,20 \mathrm{~m}$. Na Tabela 1 , são apresentados os dados dos atributos químicos do solo da área experimental antes da instalação do experimento.

Tabela 1. Atributos químicos do solo da área experimental

\begin{tabular}{ccccc|cc|ccc}
\hline $\mathrm{Ca}$ & $\mathrm{Mg}$ & $\mathrm{K}$ & $\mathrm{Al}$ & $\mathrm{H}$ & $\mathrm{P}(\mathrm{Mel})$ & $\mathrm{K}$ & $\mathrm{pH}$ & $\mathrm{V}$ & M.O. \\
\hline \multicolumn{4}{c}{$\mathrm{cmol}_{\mathrm{c} \cdot} \cdot \mathrm{dm}^{3}$} & & \multicolumn{2}{|c|}{$\mathrm{mg} \cdot \mathrm{dm}^{3}$} & $\mathrm{CaCl}_{2}$ & $\%$ & $\mathrm{~g} / \mathrm{kg}$ \\
\hline 2,7 & 0,9 & 0,13 & 0 & 1,9 & 17 & 51 & 5,6 & 66,1 & 39 \\
\hline
\end{tabular}

A semeadura manual foi realizada no dia 22 de novembro de 2003, empregando-se uma densidade de 20 sementes por metro linear. As parcelas foram constituídas por quatro linhas de cinco metros lineares, espaçadas 0,60 m. As adubações nitrogenada e potássica de cobertura foram parceladas em duas vezes, sendo que a primeira aplicação, correspondendo à metade da dose, ocorreu dia 24/12/2003 e a segunda dia 05/01/2004.

Os tratamentos foram constituídos por três doses de nitrogênio (0; 60 e 120 kg.ha-1), sob forma de sulfato de amônio, e quatro cultivares de sorgo 
forrageiro: BR 700 (porte médio, com tanino), 1F 305, 0369267 e 0369255 (porte alto, sem tanino); todos com colmo seco, sendo que os dois últimos são genótipos experimentais fornecidos pela Embrapa Milho e Sorgo, localizada em Sete Lagoas - MG. Foi utilizado o delineamento experimental em blocos casualizados em esquema fatorial $4 \times 3$, com quatro repetições.

O corte manual de avaliação foi realizado no dia 13/03/2004, quando os grãos apresentavam-se no estádio pastoso, tendendo para farináceo, e apenas as duas fileiras centrais de cada parcela foram cortadas, descartando-se as duas externas, além de $0,50 \mathrm{~m}$ das extremidades. As plantas foram cortadas a dez centímetros do solo, pesadas e imediatamente trituradas em picadeira estacionária, em partículas de aproximadamente $1 \mathrm{~cm}$. Após a homogeneização manual, procedeu-se a retirada de uma sub-amostra (300 g) que foi pesada e levada à estufa de ventilação forçada a $65^{\circ} \mathrm{C}$, durante $72 \mathrm{~h}$. Posteriormente, foram moídas em moinho tipo Willey com peneira de $1 \mathrm{~mm}$ para a determinação da matéria pré-seca. O material restante foi utilizado no processo de ensilagem dos tratamentos e repetições.

Como mini-silos (unidades experimentais) foram utilizados baldes plásticos com capacidade para 15 litros, com altura de $0,31 \mathrm{~m}$, raios inferior e superior de $0,13 \mathrm{~m}$ e $0,15 \mathrm{~m}$, respectivamente, e lacrados com tampas próprias de encaixe, para garantir vedação adequada, e adaptadas com válvulas do tipo Bunsen, para que possibilitasse o escape de gases e a avaliação das perdas gasosas durante o armazenamento. No fundo de cada balde foram colocados quatro quilos de uma mistura de britas (zero e um), separadas da silagem por fina camada de tecido (TNT), o que evitou que a forragem entrasse em contato com a brita, e dessa forma permitiu que o efluente fosse drenado e, posteriormente, quantificado por diferença de peso.

Antes da ensilagem, o conjunto constituído por balde, tampa com válvula de Bunsen, brita e tecido foram pesados. No enchimento dos silos experimentais, pequenas camadas de forragem (aproximadamente $\quad 0,30 \mathrm{~m}$ ) foram sendo acondicionadas e compactadas com o pé dentro dos baldes, com capacidade para, aproximadamente, seis quilos de forragem, de modo a possibilitar que todos os mini-silos (tratamentos e repetições) pudessem apresentar semelhança em relação à pressão de compactação e densidade no fechamento, na tentativa de minimizar diferenças no processamento.

Por ocasião da abertura, os mini-silos cheios e ainda fechados foram pesados e a diferença de peso determinada em relação ao peso verificado no momento da vedação correspondeu às perdas de massa sob a forma de gases (Equação 1).

$$
G=\frac{(P f e-P a b)}{M F f e \times M S f e} \times 1000
$$

Em que: $\mathrm{G}=$ perda por gases (\% MS); Pfe = peso do balde cheio no momento de vedação (kg); $\mathrm{Pab}=$ peso do balde cheio na abertura (kg); MFfe = massa de forragem no no momento de vedação $(\mathrm{kg})$; MSfe = teor de matéria seca da forragem no momento de vedação (\% MS).

Para a quantificação dos efluentes, após a retirada da silagem, procedeu-se a pesagem do balde + britas + tecido (TNT) + tampa e subtraiu-se deste valor o peso do conjunto antes do processo de ensilagem, com a brita seca, o que permitiu estimar a produção de efluente, o qual foi drenado (Equação 2).

$$
E=\frac{(P a b-P f e)}{M F f e} \times 1000
$$

Em que: $\mathrm{E}=$ produção de efluente $(\mathrm{kg}$. t-1 massa verde); $\mathrm{Pab}=$ peso do conjunto (balde + tampa + brita + tecido) vazio na abertura, $(\mathrm{kg})$; $\mathrm{Pfe}=$ peso do conjunto (balde + tampa + brita + tecido) vazio no momento de vedação, (kg); MFfe = massa de forragem no momento de vedação $(\mathrm{kg})$.

Os mini-silos experimentais foram abertos em $10 / 04 / 2005$, quando se retiraram duas sub-amostras de aproximadamente 500 g. A primeira foi levada à estufa de ventilação forçada à temperatura de $65^{\circ} \mathrm{C}$, durante $72 \mathrm{~h}$, e posteriormente moída em moinho tipo Willey, em peneira de $1 \mathrm{~mm}$, para determinação da porcentagem de matéria seca. Utilizou-se a segunda sub-amostra para extração do suco da silagem, com o auxílio de uma prensa hidráulica. Após a retirada do suco, o material foi filtrado e imediatamente mensurado o potencial hidrogeniônico $(\mathrm{pH})$. Em seguida, o material foi armazenado em freezer à temperatura de $-5^{\circ} \mathrm{C}$, para a determinação dos (AGV) - ácidos graxos voláteis -, segundo metodologia descrita por SILVA \& QUEIROZ, (2002).

Utilizou-se o programa estatístico Sisvar (FERREIRA, 2008), sendo empregado o teste de Tukey a 5\% de probabilidade para a comparação entre as médias de tratamentos. $\mathrm{O}$ ajuste das médias por regressão não foi implementado em razão do pequeno número de doses utilizadas, o que não permitiria uma descrição adequada da resposta à adubação nitrogenada, sabidamente de comportamento curvilíneo.

\section{RESULTADOS E DISCUSSÃO}

Foram verificadas interações entre os híbridos e 
as doses de $\mathrm{N}$ avaliadas pela análise de variância em relação aos teores de MSmo com variação de 21,6 a 28,7\% (Tabela 2).

Esses teores determinados nos híbridos avaliados, todos de colmo seco, encontram-se abaixo do limite de 30 a 35\%, sugerido por (ARAUJO, 2007) como ideal para que haja o favorecimento da fermentação láctica. Entretanto, tais valores se encontram próximos de 25\%, como proposto por McDONALD et al. (1991), e dentro da faixa estabelecida por MEESKE et al. (1993), que obtiveram silagens com bons padrões de fermentação, quando a matéria original apresentava variação de 20 a $29 \%$ de MS, porém, com níveis de carboidratos solúveis adequados.

Tabela 2. Teores de matéria seca e proteína bruta da matéria original (MSmo; PBmo) e silagem (MSs; PBs) e potencial hidrogeniônico $(\mathrm{pH})$ da silagem de híbridos de sorgo avaliados sob doses de nitrogênio

\begin{tabular}{|c|c|c|c|c|c|}
\hline & \multicolumn{5}{|c|}{ Doses de N (kg.ha $\left.{ }^{-1}\right)$} \\
\hline & Cultivar & 0 & 60 & 120 & Média \\
\hline \multirow{5}{*}{ MSmo (\%) } & $1 \mathrm{~F} 305$ & $22,1^{\mathrm{bB}}$ & $21,6^{\mathrm{CB}}$ & $25,7^{\mathrm{bA}}$ & $23,2^{b}$ \\
\hline & 0369267 & $24,7^{\mathrm{aAB}}$ & $26,6^{\mathrm{aA}}$ & $24,1^{\mathrm{bB}}$ & $25,2^{\mathrm{a}}$ \\
\hline & 0369255 & $21,8^{\mathrm{bB}}$ & $23,4^{\text {bсAB }}$ & $25,0^{\mathrm{bA}}$ & $23,4^{\mathrm{b}}$ \\
\hline & BR 700 & $25,8^{\mathrm{aB}}$ & $24,0^{\mathrm{bB}}$ & $28,7^{\mathrm{aA}}$ & $26,01^{\mathrm{a}}$ \\
\hline & Média & $23,6^{\mathrm{B}}$ & $23,9^{\mathrm{B}}$ & $25,8^{\mathrm{A}}$ & 24,4 \\
\hline \multirow{5}{*}{ MSs (\%) } & $1 F 305$ & $27,1^{\mathrm{B}}$ & $29,6^{\mathrm{aA}}$ & $26,2^{\mathrm{bB}}$ & 27,6 \\
\hline & 0369267 & $27,5^{\mathrm{B}}$ & $26,2^{\mathrm{bB}}$ & $29,8^{\mathrm{aA}}$ & 27,8 \\
\hline & 0369255 & $27,6^{\mathrm{A}}$ & $27,7^{\mathrm{bA}}$ & $27,8^{\mathrm{bA}}$ & 27,7 \\
\hline & BR 700 & $27,8^{\mathrm{A}}$ & $27,6^{\mathrm{bA}}$ & $27,7^{\mathrm{bA}}$ & 27,7 \\
\hline & Média & 27,5 & 27,8 & 27,9 & 27,7 \\
\hline \multirow{5}{*}{ PBmo (\%) } & $1 F 305$ & 6,7 & 7,4 & 7,2 & 7,1 \\
\hline & 0369267 & 7,1 & 6,6 & 6,9 & 6,9 \\
\hline & 0369255 & 6,6 & 7,5 & 6,9 & 7,0 \\
\hline & BR 700 & 7,5 & 6,4 & 6,9 & 6,9 \\
\hline & Média & 7,0 & 6,9 & 7,0 & 7,0 \\
\hline \multirow{5}{*}{ PBs (\%) } & $1 \mathrm{~F} 305$ & $6,7^{\mathrm{B}}$ & $7,4^{\mathrm{aA}}$ & $6,4^{\mathrm{Cc}}$ & 6,8 \\
\hline & 0369267 & $6,8^{\mathrm{B}}$ & $6,2^{\mathrm{CC}}$ & $7,5^{\text {Аа }}$ & 6,8 \\
\hline & 0369255 & $6,8^{A}$ & $6,9^{\mathrm{bA}}$ & $6,9^{\mathrm{bA}}$ & 6,8 \\
\hline & BR 700 & $6,9^{\mathrm{A}}$ & $6,8^{\mathrm{bA}}$ & $6,9^{\mathrm{bA}}$ & 6,9 \\
\hline & Média & 6,8 & 6,8 & 6,9 & 6,8 \\
\hline \multirow{5}{*}{$\mathrm{pH}$} & $1 \mathrm{~F} 305$ & 4,0 & 4,0 & 3,9 & 4,0 \\
\hline & 0369267 & 3,9 & 3,9 & 4,0 & 3,9 \\
\hline & 0369255 & 3,9 & 4,0 & 4,3 & 4,1 \\
\hline & BR 700 & 4,0 & 3,8 & 4,3 & 4,0 \\
\hline & Média & 3,9 & 3,9 & 4,1 & 4,0 \\
\hline
\end{tabular}

Valores na coluna, dentro de cada variável, seguidos por letras minúsculas diferentes, e valores na linha, dentro de cada dose, seguidos por letras maiúsculas distintas, diferem entre si pelo teste Tukey (5\% de probabilidade). CV: MSs: 3,24\%; PBs: 2,32\%; $\mathrm{pH}: 7,25 \%$.

Os baixos teores de MS podem ser atribuídos à baixa participação da panícula na matéria original (PAIVA, 1976). Nesse sentido, SILVA et al. (1999) afirmaram que essa é a fração que mais contribui para a elevação dos teores de matéria seca no sorgo destinado à ensilagem, o que corrobora com os estudos de ARAÚJO (2007), que determinaram correlações de 0,76 e 0,80 , respectivamente, entre a porcentagem de panículas e o teor de matéria seca total do material original. Os híbridos avaliados apresentaram proporção de panículas na composição da matéria original com variação de 10\% (0369 267) a $17,5 \%$ (BR 700), bastante inferior aos $40 \%$ sugeridos por SILVA et al. (1999), como sendo a participação adequada dessa estrutura da planta de sorgo para a obtenção de uma silagem de boa qualidade.

Os teores de MSs diferiram $(\mathrm{P}<0,05)$ apenas entre os híbridos 1F305 e 0369 267, em relação aos demais, com variação de 26,2 a 29,6\%, respectivamente. Em função das doses de $\mathrm{N}$ aplicadas, os cultivares diferiram $(\mathrm{P}<0,05)$ entre os conteúdos de MSs nas doses equivalentes às aplicações de 60 e 120 kg.ha-1 de $\mathrm{N}$, com médias dos tratamentos de 27,8 e 27,9\%, respectivamente. No presente trabalho, os valores médios de MSmo e MSs foram de $24,9 \%$ e de $27,7 \%$, sendo, portanto, bastante semelhantes aos relatados por BRITO et al. 
(2000) de 27,4\%, na matéria original e 28,5\%, nas silagens, enquanto ROCHA JÚNIOR et al. (2000) determinaram teores de 28,1 a 29,5\%; 34,3 a $37,0 \%$ e 28,2 a $30,3 \%$, na matéria original e nas respectivas silagens. Tendo em vista que os genótipos avaliados apresentavam colmos secos e foram cortados no estádio de maturação adequado, os baixos valores de MSmo são atribuídos à baixa proporção de panícula na matéria original. Portanto, a produção de efluentes observada durante o processo fermentativo pode ser resultante do somatório dos parâmetros teor de MS e o eficiente processo de compactação durante o enchimento dos silos, o que proporcionou produção de efluente, com a consequente elevação dos teores de MS do material ensilado.

Os teores de $\mathrm{PBmo}$ não diferiram $(\mathrm{P}>0,05)$ entre os cultivares, assim como em função das doses de $\mathrm{N}$ aplicadas. Por outro lado, nas silagens, os valores de $\mathrm{PBs}$ diferiram $(\mathrm{P}<0,05)$ apenas entre os híbridos 1F305 e 0369 255. Dentre os cultivares observou-se diferença significativa nos conteúdos de $\mathrm{PBs}$ nas doses de $\mathrm{N}$ equivalentes às aplicações de 60 e 120 kg.ha-1, cujas médias dos tratamentos foram de 6,8 e $6,9 \%$, respectivamente. Observa-se que os valores médios de $\mathrm{PB}$ da matéria original são semelhantes aos determinados nas silagens, os quais se encontram no limite de $7,0 \%$ que, segundo CHURCH (1988) e VAN SOEST (1994), são suficientes para fornecer nitrogênio para a adequada fermentação microbiana do rúmen. A semelhança entre os valores médios de $\mathrm{PB}$ determinados na matéria original e nas silagens nesta pesquisa é característica da ocorrência de um processo fermentativo adequado e corroboram as afirmações de VAN SOEST (1994) de que os teores de PB não variam com o processo de ensilagem, muito embora as frações nitrogenadas possam apresentar alterações em diferentes proporções.

Com relação aos valores médios de $\mathrm{pH}$, observa-se que não diferiram $(\mathrm{P}>0,05)$ entre as cultivares $\mathrm{e}$ as doses de $\mathrm{N}$ aplicadas. Em experimento conduzido com sete híbridos de sorgo de diferentes portes e suculência do colmo, cortados aos 102 dias de crescimento vegetativo, com abertura dos silos aos 52 dias, ROCHA JÚNIOR et al. (2000) determinaram $\mathrm{pH}$ com variação de 3,5 a 4,3, enquanto o teor de ácido lático variou de $1,20 \%$ a $1,90 \%$. Os valores de $\mathrm{pH}$ encontram-se numa faixa bastante semelhante aos encontrados neste trabalho, porém, os teores de ácido lático são inferiores (Tabela 3). Por outro lado, RODRIGUES et al. (2002) avaliaram o híbrido AG 2005, cortado aos 97 dias, e relataram $\mathrm{pH}$ de 3,7 , enquanto os valores médios de ácido lático foram da ordem de 6,1\%.

Silagens com alto teor de umidade são mais propensas a desenvolver fermentações indesejáveis, e apresentam também maior resistência à redução do pH. Segundo McDONALD et al. (1991), quanto menor o teor de MS, mais baixo deverá ser o $\mathrm{pH}$, para que ocorra a inibição do desenvolvimento de microrganismos perniciosos ao processo. As silagens caracterizadas como de boa qualidade devem apresentar $\mathrm{pH}$ na faixa de 4,2, o que evita a proteólise e a consequente produção de ácido butírico. Silagens com baixos teores de MS produzem perdas de nutrientes através do efluente, o que promove a redução do seu valor nutritivo (McDONALD et al., 1991). No presente trabalho, as silagens apresentaram valores médios de $\mathrm{pH}$ com variação de 3,9 a 4,3 o que, de acordo com PAIVA (1976), as classifica como de "boa qualidade". Segundo McDONALD et al. (1991), em silagens com teores de MS acima de 35\%, o pH torna-se um parâmetro de menor relevância no processo de avaliação, o que corrobora os resultados observados nesta pesquisa, já que os teores de MS determinados na matéria original se encontram abaixo daqueles considerados ideais, porém, propiciam valores adequados de $\mathrm{pH}$ nas silagens (BORGES et al., 1997), fato este que pode ser atribuído ao sucesso do processo de compactação exercido nos silos experimentais.

Na Tabela 3, são apresentados os teores médios dos ácidos láticos, acético, butírico e propiônico, determinados nas silagens de quatro híbridos de sorgo, sob doses de nitrogênio. A determinação dos teores dos ácidos lático, acético e butírico e suas correlações são muito importantes no processo de avaliação dos padrões de fermentação das silagens.

Através da análise de variância foram observadas interações nos teores de ácido lático entre os híbridos avaliados, exceto o $1 \mathrm{~F} 305$, e as doses de N aplicadas, com variação de 3,1 a 5,6\%.

Os valores de ácido lático determinados no presente trabalho vão de encontro às afirmações de MOISIO \& HEIKONEM (1994) de que esses conteúdos devem aparecer em maior porcentagem que os demais, uma vez que todos os ácidos produzidos durante o processo fermentativo contribuem para a redução do $\mathrm{pH}$ da silagem e o ácido lático exerce fundamental importância nesse processo, em função de apresentar maior constância de dissociação que os demais.

Tomando-se por base os critérios de classificação estabelecidos por ROTH \& UNDERSANDER (1995), silagens com valores de ácido lático na faixa de $4 \%$ a $6 \%$ são consideradas como de "muito boa qualidade". Neste trabalho, os valores determinados apresentaram variação de 3,1 a 5,6\%, o que permite classificá-las como de "boa qualidade”, não só em função dos valores de ácido lático, mas principalmente devido aos demais parâmetros avaliados, exceto ácido butírico.

Os teores de ácido acético diferiram $(\mathrm{P}<0,05)$ apenas para o híbrido BR 700, com média de 1,4\% e 
não foi determinada diferença significativa em função das doses de $\mathrm{N}$ avaliadas. Teores de ácido acético da ordem de 1,17 a 1,54\% foram relatados por RODRIGUES et al. (1999) quando avaliaram quatro cultivares de sorgo, com baixo ou alto teor de tanino. Os teores de ácido acético apresentaram variação de 1,0 a $1,7 \%$, sendo, portanto inferior ao limite de 2,0\% que, de acordo com ROTH \& UNDERSANDER (1995), é o referencial para classificar as silagens como de "boa qualidade". Ainda segundo os autores, elevados teores de ácido acético podem interferir na fermentação láctica. De acordo com TOMICH et al. (2003), os teores de ácido acético e butírico se relacionam com menores taxas de decréscimo de valores de $\mathrm{pH}$. Isso corresponde, principalmente, às ações mais prolongadas de enterobactérias e bactérias lácticas heterofermentativas, embora, em menor escala, também sejam produzidas por clostrídios. Portanto, as silagens bem preservadas devem apresentar baixíssimos teores de ácido acético, o que reafirma os resultados obtidos neste trabalho, uma vez que os valores se encontram abaixo de 2,0\%, conforme estabelecem ROTH \& UNDERSANDER (1995).

Tabela 3 - Porcentagem dos ácidos lático, acético, butírico e propiônico determinados nas silagens de híbridos de sorgo, sob doses de nitrogênio

\begin{tabular}{|c|c|c|c|c|c|}
\hline \multirow[t]{2}{*}{ Ácidos } & \multicolumn{5}{|c|}{ Doses de $\mathrm{N}\left(\mathrm{kg} \mathrm{ha}^{-1}\right)$} \\
\hline & Cultivar & 0 & 60 & 120 & Média \\
\hline \multirow{5}{*}{ Lático } & $1 \mathrm{~F} 305$ & $3,4^{\mathrm{dA}}$ & $3,6^{\mathrm{bA}}$ & $3,8^{\mathrm{aA}}$ & $3,6^{b}$ \\
\hline & 0369267 & $6,2^{\mathrm{aA}}$ & $3,6^{\mathrm{bB}}$ & $3,8^{\mathrm{aB}}$ & $4,5^{\mathrm{a}}$ \\
\hline & 0369255 & $4,8^{\mathrm{bA}}$ & $3,1^{\mathrm{bB}}$ & $2,3^{\mathrm{bC}}$ & $3,4^{\mathrm{b}}$ \\
\hline & BR 700 & $4,0^{\mathrm{CB}}$ & $5,6^{\mathrm{aA}}$ & $4,0^{\mathrm{aB}}$ & $4,5^{\mathrm{a}}$ \\
\hline & Média & $4,6^{\mathrm{A}}$ & $4,0^{\mathrm{B}}$ & $3,5^{\mathrm{C}}$ & 4,0 \\
\hline \multirow{5}{*}{ Acético } & $1 \mathrm{~F} 305$ & 1,5 & 1,3 & 1,0 & 1,3 \\
\hline & 0369267 & 1,5 & 1,2 & 1,6 & 1,4 \\
\hline & 0369255 & 1,7 & 1,6 & 1,4 & 1,5 \\
\hline & BR 700 & $1,4^{\mathrm{AB}}$ & $1,6^{\mathrm{A}}$ & $1,1^{\mathrm{B}}$ & 1,4 \\
\hline & Média & 1,5 & 1,4 & 1,3 & 1,4 \\
\hline \multirow{5}{*}{ Butírico } & $1 \mathrm{~F} 305$ & 0,7 & 0,1 & 0,6 & 0,5 \\
\hline & 0369267 & 0,0 & 0,3 & 0,6 & 0,3 \\
\hline & 0369255 & 0,6 & 0,9 & 1,3 & 0,9 \\
\hline & BR 700 & 0,2 & 0,0 & 1,2 & 0,5 \\
\hline & Média & 0,4 & 0,3 & 0,9 & 0,5 \\
\hline \multirow{5}{*}{ Propiônico } & $1 \mathrm{~F} 305$ & $0,3^{\mathrm{aA}}$ & $0,2^{\mathrm{bB}}$ & $0,2^{\mathrm{bC}}$ & $0,2^{b}$ \\
\hline & 0369267 & $0,2^{\mathrm{bA}}$ & $0,1^{\mathrm{cC}}$ & $0,2^{\mathrm{bB}}$ & $0,2^{\mathrm{c}}$ \\
\hline & 0369255 & $0,2^{\mathrm{bB}}$ & $0,3^{\mathrm{aA}}$ & $0,2^{\mathrm{aB}}$ & $0,2^{\mathrm{a}}$ \\
\hline & BR 700 & $0,2^{\mathrm{cA}}$ & $0,2^{\mathrm{bA}}$ & $0,2^{\mathrm{bA}}$ & $0,2^{\mathrm{c}}$ \\
\hline & Média & $0,2^{\mathrm{A}}$ & $0,2^{\mathrm{B}}$ & $0,2^{\mathrm{C}}$ & 0,2 \\
\hline
\end{tabular}

Valores na coluna, dentro de cada variável, seguidos por letras minúsculas diferentes, e valores na linha, dentro de cada dose, seguidos por letras maiúsculas distintas, diferem entre si pelo teste Tukey ( $5 \%$ de probabilidade). CV (Lático) $=6,72 \%$; CV $($ Acético $)=22,17 \%$; CV (Propiônico) = 7,13\%; CV (Butírico $)=$ $158,63 \%$.
As concentrações de ácido butírico não diferiam $(\mathrm{P}>0,05)$ entre os genótipos e as doses de nitrogênio. ROCHA JÚNIOR et al. (2000) determinaram ácido butírico de 0,00 a 0,09\%, enquanto RODRIGUES et al. (2002) não obtiveram produção desse ácido.

Quanto às concentrações de ácido propiônico, foram observadas inteirações entre os cultivares e as doses de N, com exceção do (BR 700), com variação de 0,1 a $0,3 \%$.

ROCHA JÚNIOR et al. (2000) determinaram valores de ácido propiônico de $0,00 \%$ a $0,36 \%$. De acordo com ROTH \& UNDERSANDER (1995), a presença do ácido propiônico acima do limite estabelecido significa a degradação do ácido lático por bactérias butíricas, situação totalmente descartada no presente trabalho, visto que os teores do referido ácido se encontram abaixo de 0,5\%.

De acordo com os critérios estabelecidos ROTH \& UNDERSANDER (1995), uma silagem para ser classificada como "muito boa", deverá apresentar: ácido lático de 4,0\% a 6,0\%; ácido acético $<2,0 \%$; ácido propiônico $<0,50 \%$. As silagens produzidas nesta pesquisa podem, desta forma, ser consideradas de muito boa qualidade, exceto em relação ao ácido butírico que se encontra ligeiramente acima do limite de $<0,10 \%$, estabelecido pelo referido autor.

Na Tabela 4, são apresentados os valores médios determinados para densidade da silagem no momento de enchimento (Den) e por ocasião da abertura dos silos (Dab), produção de gás (Gás) e de efluente (Efl).

Os híbridos não diferiram em relação à Den, exceto o 0369 255, cujo valor médio foi de 509,9 kg.m-3 de silagem no momento do enchimento. Em função das doses de $\mathrm{N}$, a análise de variância detectou interações entre todos os cultivares nas aplicações equivalentes a 60 e 120 kg.ha- 1 de N, com variação de 379,2 a 584,4 kg.m-3 de silagem.

Segundo SENGER et al. (2005), as silagens de milho com teor de MS acima de $28 \%$, se bem compactadas, possibilitam densidades superiores a 650 kg.m-3, o que permite a preservação de maiores quantidades de açúcares para o processo fermentativo. Nesse sentido, MULLIGAN et al. (2002) afirmaram que silagens mal compactadas (nível de compactação abaixo de 300 kg.m-3), determinam maior atividade de enzima proteolítica, responsável pela transformação do nitrogênio protéico em NNP.

A densidade e a MS do material ensilado determinam a porosidade da silagem afetando a taxa de penetração do ar na massa ensilada durante a descarga do silo. Portanto, maiores densidades diminuem os custos anuais de estocagem em função 
de aumentar a quantidade de silagem estocada no silo e por diminuir as perdas do material ensilado. Desta forma, quanto menor a densidade, maiores serão as perdas (RUPPEL et al., 1995). No presente trabalho, as Den apresentaram variação média de 379,4 (BR 700) a 584,4 kg.m (0369 255), enquanto a Dab apresentou valores ligeiramente mais baixos 343,9 (0369 267) a 523,6 kg.m (0369 255), em função da elevação dos teores de MS, decorrente da produção de efluentes. Entretanto, as Dab se encontram acima do limite de 300 kg.m ${ }^{3}$ estabelecido por MULLIGAN et al. (2002), como sendo determinante de silagens mal compactadas e se situam abaixo de $650 \mathrm{~kg} \cdot \mathrm{m}^{3}$ estabelecido por SENGER et al. (2005), como silagem bem compactadas e, consequentemente, tidas como de boa preservação.

Tabela 4 - Valores médios das densidades da silagem no momento de enchimento (Den) (Den) e na abertura dos silos (Dab), em kg.m ${ }^{-3}$, perda por gases (Gas) em (\%MS), produção de efluente (Efl) kg.t ${ }^{-1}$ de massa verde, determinadas nas silagens de cultivares de sorgo, sob doses de nitrogênio

\begin{tabular}{|c|c|c|c|c|c|}
\hline & \multicolumn{5}{|c|}{ Doses de N (kg.ha ${ }^{-1}$ ) } \\
\hline & Cultivar & 0 & 60 & 120 & Média \\
\hline \multirow{5}{*}{ Den } & $1 \mathrm{~F} 305$ & $418,9^{\mathrm{a} A}$ & $424,0^{\text {abA }}$ & $420,0^{\mathrm{bA}}$ & $421,0^{b}$ \\
\hline & 0369267 & $383,6^{\text {aA }}$ & $395,8^{\mathrm{abA}}$ & $406,0^{\mathrm{bA}}$ & $395,2^{b}$ \\
\hline & 0369255 & $454,9^{\mathrm{aB}}$ & $490,3^{\mathrm{aB}}$ & $584,4^{\mathrm{aA}}$ & $509,9^{a}$ \\
\hline & BR 700 & $399,6^{\text {aA }}$ & $379,4^{\mathrm{bA}}$ & $402,7^{\mathrm{bA}}$ & $393,9^{b}$ \\
\hline & Média & $414,2^{\mathrm{A}}$ & $422,4^{\mathrm{A}}$ & $453,3^{A}$ & 430,0 \\
\hline \multirow{5}{*}{ Dab } & $1 \mathrm{~F} 305$ & $368,7^{\mathrm{aA}}$ & $371,2^{\mathrm{aA}}$ & $378,3^{\mathrm{bA}}$ & $372,8^{b}$ \\
\hline & 0369267 & $343,9^{\text {aA }}$ & $347,8^{\text {aA }}$ & $372,7^{\mathrm{bA}}$ & $354,7^{b}$ \\
\hline & 0369255 & $407,0^{\mathrm{aB}}$ & $434,1^{\mathrm{aB}}$ & $523,6^{\text {aA }}$ & $454,9^{a}$ \\
\hline & BR 700 & $362,3^{\text {aA }}$ & $340,5^{\text {aA }}$ & $365,1^{\text {bA }}$ & $356,0^{b}$ \\
\hline & Média & $370,5^{\mathrm{A}}$ & $373,4^{\mathrm{A}}$ & $409,9^{\mathrm{A}}$ & 384,6 \\
\hline \multirow{5}{*}{ Gás } & $1 \mathrm{~F} 305$ & 1,7 & 2,7 & 2,4 & 2,3 \\
\hline & 0369267 & 1,5 & 2,0 & 2,0 & 1,9 \\
\hline & 0369255 & 1,8 & 2,1 & 2,2 & 2.0 \\
\hline & BR 700 & 1,5 & 1,9 & 1,6 & 1,7 \\
\hline & Média & 1,6 & 2,2 & 2,1 & 1,9 \\
\hline \multirow{5}{*}{ Efl } & $1 F 305$ & 75,0 & 60,0 & 57,5 & 64,2 \\
\hline & 0369267 & 28,7 & 67,5 & 53,7 & 50,0 \\
\hline & 0369255 & 62,5 & 100,0 & 133,7 & 98,75 \\
\hline & BR 700 & 60,0 & 66,2 & 42,5 & 56,2 \\
\hline & Média & 56,6 & 73,4 & 71,9 & 67,3 \\
\hline
\end{tabular}

Valores na coluna, dentro de cada variável, seguidos por letras minúsculas diferentes, e valores na linha, dentro de cada dose, seguidos por letras maiúsculas distintas, diferem entre si pelo teste Tukey (5\% de probabilidade). CV (Den) $=12,33 \%$; CV $(\mathrm{Dab})=13,12 \%$; CV $($ GAS $)=28,67 \%$; CV $($ EFL $)=35,56 \%$.
A produção de Gás e Efluentes (Efl) não diferiu $(\mathrm{P}>0,05)$ entre híbridos e doses de $\mathrm{N}$ avaliadas. Segundo AMARAL et al (2007), a formação de gás na silagem é resultante de fermentações secundárias, exercida por enterobactérias, bactérias do gênero Clostridium e microrganismos aeróbicos, que normalmente crescem em meios com $\mathrm{pH}$ mais elevado.

Sabe-se que a produção de efluentes é influenciada pelo teor de MS, natureza do silo, grau de compactação exercido, além do processamento físico da forragem. Quando o material é ensilado com alta concentração de umidade, as perdas de MS através do efluente podem alcançar até $10 \%$, por outro lado, quando o teor de MS se encontra na faixa de $30 \%$, a produção de efluente torna-se insignificante (HAIGH, 1999). REZENDE (2008) avaliou a perda de efluentes em silagem de cana-deaçúcar com variação de 3,99 kg.t-1 de matéria original, quando a silagem apresentava $43,7 \%$ de MS a 57,67 kg/t na matéria original nas silagens com $21,3 \%$ de MS, enquanto nas silagens produzidas com capim-elefante, as perdas foram da ordem de 1,56 kg.t-1 na matéria original nas silagens com 34,9\% de MS a 53,7 kg/t nas silagens com 21,3\% de MS.

Segundo VAN SOEST (1994) a produção excessiva de efluentes ao longo do processo fermentativo ocasiona a elevação de componentes fibrosos, principalmente em decorrência da lixiviação dos compostos solúveis em água. Normalmente os constituintes da parede celular se elevam durante o armazenamento da silagem, em função da redução do nível de carboidratos solúveis através do processo fermentativo e devido às perdas de MS através do efluente e gases de fermentação (SCHIMIDT et al, 2007).

\section{CONCLUSÕES}

Considerando-se os teores dos AGVs, valores de $\mathrm{pH}$ e \% de MS, pode-se afirmar que o processo fermentativo transcorreu de forma adequada, proporcionando uma silagem de boa qualidade.

\section{REFERÊNCIAS}

AMARAL, R. C.; BERNARDES, T. F.; SIQUEIRA, G. R.; REIS, R. A. Características fermentativas e químicas de silagens de capim-marandu produzidas com quatro pressões de compactação. Revista Brasileira de Zootecnia, v. 36, n. 3, p. 532-539, 2007.

ARAUJO, V. L., RODRIGUES, N. M.; GONÇALVES, L. C.; RODRIGUES, J. A. S.; BORGES, I.; BORGES, A. L. C. C.; SALIBA, E. O. S. Qualidade das silagens de três 
híbridos de sorgo ensilados em cinco diferentes estádios de maturação. Arquivos Brasileiros de Medicina Veterinária e Zootecnia, v. 59, p. 168-174, 2007.

BORGES, A. L. C. C.; GONÇALVES, L. C.; RODRIGUEZ, N, M.; NOGUEIRA, F.S.; BORGES, I. Qualidade de silagens de híbridos de sorgo de porte alto com diferentes teores de tanino e de umidade do colmo. I - pH e teores de matéria seca e de ácidos graxos durante a fermentação. Arquivo Brasileiro de Medicina Veterinária e Zootecnia, v. 49 n.4, p 441-452, 1997.

BRASIL. Ministério da Agricultura e Reforma Agrária. Secretaria Nacional de Irrigação, Departamento Nacional de Meteorologia. Normais Climatológicas: 1961-1990. Brasília, 84p., 1992.

BRITO, A. F., GONÇALVES, J. A. S., RODRIGUES, V. R., ROCHA JÚNIOR., BORGES, I.; RODRIGUES, N. M. Avaliação da silagem de sete genótipos de sorgo (Sorghum bicolor (L) Moench). II. Padrão de fermentação. Arquivo Brasileiro de Medicina Veterinária e Zootecnia, v. 52, n. 52, 2000.

CARVALHO, D. D.; ANDRADE, J.B.; BIONDI, P. Estádio de maturação na produção e qualidade da silagem de sorgo I: Produção de matéria seca e de proteína bruta. Boletim de Indústria Animal, v.49, n.2, p.91-99, 1992.

CURCH, D. C. The ruminant animal digestive physiology and nutrition. Prentice Hall: New Jersey, 564p, 1988.

FERREIRA, D. F. Análises estatísticas por meio do Sisvar para Windows $\quad$ Versão http://www.dex.ufla.br/ danielff/softwares.htm. Acessado em $20 / 02 / 2008$.

HAIGH, P. M. Efluent production from grass treated with additives and made in large scale bunker silos. Grass and Forage Science, v. 54, p. 208-218, 1999.

McDONALD, P., HENDERSON, A.R., HERON, S. The biochemistry of silage. 2.ed. Marlow: Chalcombe Publicatins, 1991. 340 p.

MEESKE, R.; ASHBELL, G.; WEINBERG, Z.G.; KIPNIS, T. Ensilage forage sorghum at two stages of maturity with the addition of tactic acid bacterial inoculations. Animal Feed Science and Technology, v. 43, p. 165 - 176, 1993.

MOISIO, T., HEIKONEN, M. Latic acid fermentation on silage preserved with formic acid. Animal Feed Science and Technology, v. 47, n. 1, p.107-124, 1994.

MULLIGAN, F. J., QUIRK, J., CAFFREY, P. J. Intake, digestibility, milk production and kinetics of digestion and passage for diets based on maize or grass silage fed to late lactation dairy cows. Livestock Production Sciences, v. 74, p. 113-124, 2002.

NEUMANN, M.; RESTLE, J.; ALVES FILHO, D.C.; BRONDANI, I.L.; PELLEGRINI, L.G.; FREITAS, A.K. Avaliação do Valor Nutritivo da Planta e da Silagem de diferentes Híbridos e Sorgo (Sorghum bicolor (L.)
Moench). Revista Brasileira de Zootecnia, n.1, p.293301, 2002 (suplemento).

REZENDE, A. V.; RODRIGUES, R.; BARCELOS, A. F.; CASALIS, A. O.; VALERIANO, A. R.; MEDEIROS, L. T. Qualidade bromatológica das silagens de capimelefante aditivadas com raspa de batata. Ciência e Agrotecnologia, Lavras, v.32, n. 2, p. 604-610, 2008.

ROCHA JÚNIOR, V. R.; GONÇALVES, L.C.; RODRIGUES, J.A.S.; BRITO, A.F.; BORGES, I.; RODRIGUES, N.M. Avaliação de sete genótipos de sorgo (Sorghum bicolor (L.) Moench) para produção de silagem. Arquivo Brasileiro de Medicina Veterinária de Zootecnia, v.52, n.5., p.506-511, 2000.

RODRIGUEZ, M. N., GONÇALVES, L. C., NOGUEIRA, F. A. S.; BORGES, A.L.C.C.; ZAGO, C.P. Silagem de sorgo de porte baixo com diferentes teores de tanino e de umidade no colmo. I - pH e teores de matéria seca e de ácidos graxos durante a fermentação. Arquivo Brasileiro de Medicina Veterinária e Zootecnia, v.51, p.485-490, 1999.

RODRIGUEZ, P. H. M.; SENATORE, A.L.; ANDRADE, J. T.; RUZANTE, J. M.; LUCCI, C. S.; LIMA, F. R. Efeitos da adição de inoculantes microbianos sobre a composição bromatológica e perfil fermentativo da silagem de sorgo produzida em silos experimentais. Revista Brasileira de Zootecnia, v.31, n.6, p.2373-2379, 2002.

ROTH, G., UNDERSANDER, D. Silage additives. In: Corn Silage Production Management and Feeding. MADISON: Madison American Society of Agronomy, p.27-29. 1995.

RUPPEL, K.A., PITT, R.E., CHASE, L.; GALTON, D.M. Bunker silo management and its relantionship to forage preservation on dairy farms. Journal of Dairy Science, v. 78, n. 1, p. 141-153, 1995.

SENGER, C.C.D., MÜHLBACCH, P.R.F,, SANCHEZ, L.B.M.; NETTO, D.P.; LIMA, L.D. Composição química e digestibilidade "in vitro" de silagens de milho com distintos teores de umidade e níveis de compactação. Ciência Rural, v. 35, n. 6, p. 1393-1399, 2005.

SCHIMIDT, P.; MARI, L. J.; NUSSIO, L. G.; PEDROSO, A. F.; PAZIANI, S. F.; WECHSLER, F. S. Aditivos químicos e biológicos na ensilagem de cana-deaçúcar. 1. Composição química das silagens, ingestão, digestibilidade e comportamento ingestivo. Revista Brasileira de Zootecnia, Viçosa, v. 36, n. 5, p.16661675, 2007 (supl.).

SILVA, D. J.; QUEIROZ, A. C. Análise de Alimentos: métodos químicos e biológicos. 3.ed. - Viçosa: UFV, 2002.

SILVA, F. F., GONÇALVES, L. C., RODRIGUES, J. A. S., CORRÊA, C. E. S., RODRIGUES, N.M.; BRITO, A.F. Qualidade de silagens de híbridos de sorgo (Sorghum bicolor (L.) Moench) de portes baixo, médio e alto com diferentes proporções de colmo + folhas/panícula. 2 . 
Avaliação do valor nutritivo. Revista Brasileira de Embrapa Pantanal, 2003. 20 p. (Embrapa Pantanal. Zootecnia, v.28, n.1, p. 21-29, 1999.

Documento, 57).

TOMICH, T., PEREIRA, L.G.R., GONÇALVES, L.C.; VAN SOEST, P. J. Nutritional Ecology of the TOMICH, R.G.P.; BORGES, I. Características químicas Ruminant. 2ed. Ithaca: Cornell University Press, 1994. para avaliação do processo fermentativo de silagem: $476 \mathrm{p}$.

uma proposta para qualificação da fermentação. Corumbá:

Protocolado em: 05 dez. 2006. Aceito em: 06 maio 2011. 